\title{
As Sequências Didáticas no Ensino de Ciências e Matemática no Brasil
}

\author{
Didactic Sequences in Science and Mathematics Teaching in Brazil \\ Secuencias Docentes en Ciencias y Matemáticas en Brasil
}

KÊNYA MARIA VIEIRA LOPES ${ }^{1}$, RITIANNE DE FÁTIMA SILVA DE OLIVEIRA², IDEMAR VIZOLLI $^{3}$, MARTA MARIA PONTIN DARSIE ${ }^{4}$

${ }^{1}$ Instituto Federal de Educação, Ciência e Tecnologia do Tocantins, Brasil

2 Universidade Federal do Tocantins, Brasil

${ }^{3}$ Universidade Federal do Tocantins, Brasil

${ }^{4}$ Universidade Federal de Mato Grosso, Brasil

RESUMO: Tem-se como objetivo analisar os trabalhos acadêmicos defendidos no Brasil entre os anos de 2015 a 2019 na área de concentração de Ciência e Matemática que apresentam como objeto de estudo uma proposta de Sequência Didática (SD). A presente pesquisa é de natureza qualitativa e se classifica, do ponto de vista de seus objetivos, como descritiva-exploratória. Para a busca dos trabalhos acadêmicos da plataforma da Capes, usou-se como referencial metodológico os estudos de Sampaio e Mancini (2007). Entre os aportes teóricos referenciados nos trabalhos analisados constam: Zabala, Ausubel, Delizoicov, Pais e Carvalho. Das estruturas de SDs apreendidas destacam-se as desenvolvidas com base nos 3 momentos pedagógicos cunbados por Delizoicov a partir de Freire: problematização, organização do conhecimento e aplicação do conhecimento. Observa-se que a problematização é um item comum nas estruturas das SDs. Essas que se distinguem devido às suas particularidades, e possuem como principal objetivo promover a aprendizagem significativa.

APRENDIZAGEM. CIÊNCIAS. ENSINO. MATEMÁTICA. SEQUÊNCIA DIDÁTICA.

\begin{abstract}
The objective is to analyze the academic works defended in Brazil between the years 2015 to 2019 in the area of concentration of Science and Mathematics that present as a subject of study a Didactic Sequence (SD) proposal. The present research is of a qualitative nature and is classified, from the point of view of its objectives, as descriptive-exploratory. To search for academic works on the Capes platform, the studies of Sampaio and Mancini (2007) were used as a methodological reference. Among the theoretical contributions referenced in the analyzed studies are: Zabala, Ausubel, Delizoicov, Pais and Carvalho. Of the SD structures apprehended, the ones developed based on the 3 pedagogical moments coined by Delizoicov from Freire stand out: problematization, organization of knowledge and application of knowledge. It is observed that problematization is a common item in SD structures. Those that are distinguished due to their particularities, and have as main objective to promote meaningful learning.

LEARNING. SCIENCES. TEACHING. MATHEMATICS. DIDACTIC SEQUENCE.
\end{abstract}

Os autores cedem à Revista Internacional Educon os direitos de primeira publicação do presente artigo. Aplicam-se os termos de uma licença Creative Commons Atribuição 4.0 Internacional (CC BY 4.0), que permite o uso irrestrito, a distribuição e a reprodução em qualquer meio desde que a publicaşão original seja corretamente citada. 


\begin{abstract}
RESUMEN: El objetivo es analizar los trabajos académicos defendidos en Brasil entre los años 2015 a 2019 en el área de concentración de Ciencias y Matemáticas que presentan como tema de estudio una propuesta de Secuencia Didáctica (SD). Esta investigación es de naturaleza cualitativa y se clasifica, desde el punto de vista de sus objetivos, como descriptiva-exploratoria. Para buscar trabajos académicos en la plataforma Capes, se utilizaron los estudios de Sampaio y Mancini (2007) como referencia metodológica. Entre las contribuciones teóricas a las que se hace referencia en los estudios analizados se encuentran: Zabala, Ausubel, Delizoicov, Pais y Carvalho. De las estructuras SD aprehendidas, se destacan las desarrolladas en base a los 3 momentos pedagógicos acuñados por Delizoicov de Freire: problematización, organización del conocimiento y aplicación del conocimiento. Se observa que la problematización es un elemento común en las estructuras SD. Los que se distinguen por sus particularidades y tienen como objetivo principal promover un aprendizaje significativo.
\end{abstract}

\title{
APRENDIZAJE. CIENCIAS. ENSEÑNANDO. MATEMÁTICAS. SIGUIENDO
} LA ENSEÑ $A N Z A$.

\section{Introdução}

No processo de ensino e de aprendizagem, podem-se utilizar de diversas estratégias metodológicas com vista a garantir que a ação de ensinar alcance o objetivo da ação de aprender por parte de quem ensina e ao mesmo tempo aprende e, principalmente, de quem aprende mesmo sem ensinar. A escolha da temática Sequência Didática (SD) para elaboração deste trabalho deve-se ao fato da percepção tida no decorrer de alguns estudos sobre proposta metodológica de ensino de que há educadores tratando o termo SD mesmo que sua estrutura demonstre ser apenas de um plano de aula. Contudo, compreendese que um plano de ensino/aula pode assumir características de uma SD na medida em que as relações professor e/com conteúdo, e/com aluno, e/com tempo, e/com espaço são estabelecidas na prática educativa.

As pesquisas sobre o ensino voltadas para as Ciências e Matemática tem ganhado impulso nas últimas duas décadas devido à criação, na Coordenação de Aperfeiçoamento de Pessoal de Nível Superior (Capes), da área 46. Como a implantação de programas de ensino nessa área tem sido progressiva, estimase que as produções acadêmicas que resultam da integralização de cursos de graduação e pós-graduação pelo país possam ter focalizado diversas questões-problemas encontradas no cotidiano escolar, inclusive abordando o uso de uma SD como metodologia de ensino e produto.

Nesta perspectiva, estabeleceram-se alguns questionamentos: quais são definições sobre SD apresentadas por teóricos da área da educação? Com base em qual(is) autor(es) os pesquisadores das áreas de ensino de Ciências e Matemática têm conceituado o termo Sequência Didática? Qual(is) estrutura(s) de sequência didática podem ser encontradas em trabalhos acadêmicos desenvolvidos no Brasil nas áreas de ensino de Ciências e Matemática? Tem-se como objetivo geral deste artigo analisar os trabalhos acadêmicos defendidos no Brasil entre os anos de 2015 a 2019 na área de concentração de Ciências e Matemática que apresentam como objeto de estudo uma proposta de SD. Os objetivos específicos são: apresentar algumas definições sobre SD a partir de teóricos da área de Ciências e Matemática; verificar os aportes teóricos sobre SD utilizados nos trabalhos encontrados na pesquisa junto a Capes; e apreender as estruturas das SDs de alguns deles.

A presente pesquisa é de natureza qualitativa e se classifica, do ponto de vista de seus objetivos, como descritiva-exploratória. Para a busca dos trabalhos acadêmicos da plataforma da Capes (2020) usouse como referencial metodológico os estudos de Sampaio and Mancini (2007).

Apresenta-se neste artigo os percursos metodológicos adotados na pesquisa; algumas definições atribuídas ao termo SD, seguidas da análise de trabalhos acadêmicos que apresentam como objeto de estudo uma proposta de sequência didática: suas abordagens teóricas e as estruturas das SDs. 


\section{Percursos Metodológicos}

Pela sua natureza e classificação, a presente pesquisa busca descrever características de uma determinada população, com a finalidade de identificar possíveis relações entre variáveis, aproximandose, dessa forma, da pesquisa explicativa (Gil, 2010). O trabalho foi desenvolvido em duas etapas. A primeira consistiu na revisão literária sobre as definições atribuídas ao termo SD por teóricos da área educacional que, nesse sentido, atendeu ao objetivo de: apresentar algumas definições sobre SD a partir de teóricos da área de Ciências e Matemática; e, a segunda etapa, que consistiu na consulta de trabalhos acadêmicos junto a Capes. Nessa etapa, buscou-se atender aos demais objetivos propostos no trabalho, tal como explicado a seguir.

Seguindo algumas das instruções de metodologia de revisão sugeridas por Sampaio e Mancini (2007), realizou-se, na plataforma da Capes, uma busca de dissertações e teses que apresentam como objeto de estudo uma proposta de sequência didática. As autoras alertam que antes de iniciar uma revisão é importante definir os objetivos, identificar a literatura e selecionar os estudos possíveis de serem incluídos nela. De modo resumido, o processo de revisão de literatura sugerido pelas autoras segue o fluxo de delimitar a questão científica; definir as bases de dados a serem consultadas juntamente com as palavras-chaves e estratégias de buscas; estabelecer critérios para seleção dos artigos encontrados; conduzir as buscas nas bases; aplicar os critérios de seleção e justificar possíveis exclusões; analisar os estudos incluídos na revisão; preparar um resumo sintetizando informações e, por fim, apresentar uma conclusão.

Buscando atender aos objetivos da pesquisa, incluiu-se na base escolhida a expressão "sequência didática" (com aspas). Dado esse passo, realizou-se o download dos trabalhos defendidos entre os anos de 2015 a 2019, os encontrados após aplicação dos filtros: ano (2015, 2016, 2017, 2018, 2019); área de conhecimento e área de concentração (Ensino de Ciências e Matemática). Para análise dos trabalhos, escolheu-se alguns que pudessem representar tanto as áreas de Ciências quanto a Matemática.

\section{Algumas definições atribuídas à Sequência Didática}

A sequência didática surgiu na França na década de 80, começando a ser trabalhada no Brasil na década de 90 por meio da implantação dos Parâmetros Curriculares Nacionais (PCN). Tanto na França quanto no Brasil, a SD iniciou com vistas ao ensino do idioma materno e somente depois passou a ser usada em diferentes áreas do conhecimento (Oliveira, 2013).

É consenso na academia que a definição sobre Sequência Didática, no Brasil, parte do teórico Zabala (1998). Dada tal prerrogativa, apresentar-se-ão outras definições sobre sequência didática, mesmo que não tratada com essa nomenclatura, defendidas por teóricos da área de Ciências e Matemática, tais como: Delizoicov (2008), Carvalho et al (1995), Guimarães and Giordan (2011) e Pais (2015).

Para Zabala (1998), a Sequência Didática (SD) é "um conjunto de atividades ordenadas, estruturadas e articuladas para a realização de certos objetivos educacionais, que têm um princípio e um fim conhecidos tanto pelo professor como pelos alunos” (Zabala, 1998, p. 18). É entendimento do autor que as sequências didáticas devem ser consideradas como uma maneira de situar as atividades, permitindo identificações e caracterizações preliminares na forma de ensinar, afastando a concepção de serem apenas um tipo de tarefa. O autor lembra que discutir sobre a prática educativa é uma forma de:

[...] pôr sobre a mesa os instrumentos que nos permitam introduzir nas diferentes formas de intervenção aquelas atividades que possibilitem uma melhora de nossa atuação nas aulas, como resultado de um conhecimento mais profundo das variáveis que intervêm e do papel que cada uma delas tem no processo de aprendizagem dos meninos e meninas [...]. (Zabala, 1998, p.54). 
Zabala (1998) defende que os conteúdos a serem trabalhados no processo de ensino/aprendizagem devem envolver, além dos factuais (fatos, acontecimentos, situações, fenômenos, em síntese, conteúdos conceituais), os procedimentais e atitudinais. Estes poderiam estar diretamente relacionados aos objetivos educacionais propostos por Delors (2003), respectivamente, como: aprender a conhecer, aprender a fazer/a aprender e aprender a ser/a conviver. Para Zabala (1998), uma Sequência Didática pode envolver pontos como: apresentação de uma situação problemática, problemas ou questões; respostas intuitivas ou suposições; fontes e busca de informações/soluções; elaboração de conclusões/exposição das soluções; generalização; aplicação; exercitação; prova ou exame; e avaliação.

Demonstrando defender uma concepção construtivista de educação, Zabala (1998) elenca como papel do professor no Processo de Ensino/Aprendizagem (PEA): planejar de modo flexível, de maneira que seja possível adaptar o que foi planejado às necessidades dos alunos; contar com as contribuições e os conhecimentos dos alunos durante todo o processo educativo; ajudar os alunos a encontrarem sentido no que estão fazendo; estabelecer metas ao alcance dos alunos; oferecer ajudas adequadas; promover atividade mental autoestruturante, de modo que o aluno consiga estabelecer o máximo de relações com o novo conteúdo; estabelecer um ambiente e determinadas relações com base no respeito mútuo e sentimento de confiança, promovendo autoestima e autoconceito; promover canais de comunicação; potencializar progressivamente a autonomia dos alunos; e avaliar os alunos de modo justo. Ainda para o autor, é papel do estudante: dar sentido, por meio da ajuda do professor, ao conteúdo ensinado; seguir o processo de ensino e aprendizagem situando-se nele com contribuição do professor; avaliar a própria competência, com ajuda do professor, se necessário; assumir um papel ativo e protagonista no ensino/aprendizagem tanto quanto o professor.

Observa-se que a proposição de uma situação problemática/questões e a busca da resolução de problema são pontos de partida nas estruturas de SDs defendidas por Zabala. Além disso, ao abordar sobre o PEA, o autor deixa evidente sua compreensão sobre a relevância dos estudantes, professores, gestão e ambiente escolar no desenvolvimento das atividades educativas.

Delizoicov $(2008$, p. 58) utiliza a expressão dinámica didáctico-pedagógica para se referir a uma proposta didática desenvolvida por ele a partir das obras de Freire. Acreditando que os estudantes devem se apropriar dos conhecimentos científicos de modo que consigam reinterpretar as situações, Delizoicov propôs uma dinâmica didático-pedagógica para professores da área de Ciências com base em 3 Momentos Pedagógicos (3MP): problematização inicial; organização do conhecimento e aplicação do conhecimento

Sobre o momento da problematização inicial, assim afirma Delizoicov (2008, p. 55, tradução nossa): "O ponto culminante dessa problematização é fazer com que o aluno sinta a necessidade de adquirir outros conhecimentos que não tinha antes, ou seja, se busca configurar a situação em discussão como um problema que pode originar novos conhecimentos. Nesse momento, deve-se apresentar uma situação previamente selecionada e relacionada ao tema proposto de modo que, a partir dela, possam-se introduzir os conhecimentos científicos a serem interpretados. O papel do professor é de questionar, confrontar as interpretações dos estudantes.

Assim, na organização do conhecimento "[...] os conhecimentos selecionados no processo de redução temática, articulados com a problematização inicial, são sistematicamente estudados neste momente sobre a orientação do professor". (Delizoicov, 2008, p. 56, tradução nossa). Nesse momento, há o estudo sistemático dos conhecimentos envolvidos no tema e na problematização inicial. Devem-se empregar variadas atividades, de modo que o professor possa desenvolver as conceituações que considere como essenciais para que o estudante compreenda as situações problemas elencadas na sequência didática. Cabe ao professor fazer uma mediação entre o aluno e o conhecimento científico, de modo que aquele compreenda o problema e apreenda o conhecimento.

No momento da aplicação do conhecimento, busca-se: “[...] capacitar os alunos para que usem os conhecimentos, com a perspectiva de formá-los para articular, constante e rotineiramente, o conceito científico com as situações reais. [...]”. (Ibidem, tradução nossa). Assim, o papel do professor consiste em capacitar os alunos a aplicar os conhecimentos adquiridos em sala de aula em situações reais vinculadas, 
ou não, ao tema gerador. Os estudantes devem utilizar os conhecimentos científicos explorados na organização do conhecimento articulando com situações que fazem parte de sua vivência.

Embora não utilize o termo SD, entende-se que os 3MP é uma proposição didática pela qual Delizoicov sugere a estruturação de atividades na dinâmica do processo de ensino/aprendizagem.

Carvalho et al. (1995) utilizam o termo actividades-elaboradas para referirem às atividades que tem por objetivo proporcionar ao aluno condições para que alcance o conhecimento. As autoras defendem, no ensino de Ciências e Matemática, a realização de diferentes atividades que devem estar acompanhadas de problemas, situações problematizadoras, questionadoras e de diálogo, envolvendo a estratégia de resolução de problemas e levando à introdução de conceitos para que os alunos possam construir seu conhecimento. Alertam ainda que o problema deve ser bem planejado despertando o interesse dos estudantes para a busca de solução, sendo que essa busca deve possibilitar que os estudantes explicitem os conhecimentos adquiridos. Entendem também que o erro deve ser aproveitado pelo professor, de modo que, a partir dele, o estudante assimile os conhecimentos. Por realizarem pesquisas na área, as autoras são referenciadas em diferentes trabalhados que tratam sobre SD.

Entende-se que a definição de SD por Carvalho parte da ideia das variadas atividades a serem propostas aos estudantes também pautadas na problematização, tal como defendem Delizoicov e Zabala.

Guimarães and Giordan (2011, p. 3) definem a sequência didática como sendo um instrumento que pode "se tornar importante mecanismo de socialização dos conhecimentos na escola, na comunidade escolar e na comunidade do entorno da escola". Além disso, uma SD elaborada a partir da perspectiva sociocultural pode se constituir como uma opção para minimizar as tensões de um ensino descontextualizado. Os autores, apresentando uma alternativa de estrutura de SD no ensino de Ciências, indicam como pontos para uma delas: título, público alvo, problematização, objetivos gerais, objetivos específicos, conteúdos, dinâmica, avaliação, referências bibliográficas e bibliografia empregada.

Sobre os pontos propostos para uma SD, assim definem os autores: o título é o elemento mais simples de uma SD, todavia, não pode ser menosprezado, devendo ser atrativo; a especificação do público alvo é um fato que demonstra que uma SD não é universal; enquanto a problematização é a ação que une e sustenta a relação entre os vários pontos da SD; os objetivos gerais devem ser passíveis de serem atingidos; os objetivos específicos são organizadores detalhados das intenções do ensino; os conteúdos devem promover a continuidade das variadas unidades didáticas; as dinâmicas são fundamentais para o desenvolvimento das situações de aprendizagem; a avaliação deve atender aos objetivos e conteúdos da SD; as referências bibliográficas são as utilizadas na execução das aulas; enquanto as bibliografia utilizada é a que contribuiu para a elaboração da SD (Guimarães \& Giordan, 2011).

Ao abordar sobre o ensino na área de Matemática, Pais (2015) indica que:

Uma situação didática é formada pelas múltiplas relações pedagógicas estabelecidas entre o professor, os alunos e o saber, com a finalidade de desenvolver atividades voltadas para o ensino e para a aprendizagem de um conteúdo específico. Esses três elementos componentes de uma situação didática (professor, aluno, saber) constituem a parte necessária para caracterizar o espaço vivo de uma sala de aula ( $\mathrm{ps}^{1}$. 969-970).

Para ele, uma sequência didática "é formada por um certo número de aulas planejadas e analisadas previamente com a finalidade de observar situações de aprendizagem, envolvendo os conceitos previstos na pesquisa didática" (ps. 1529). O autor compreende que as aulas da SD são sessões, não podendo ser consideradas como aulas comuns. Nesse sentido, a aplicação da sequência didática é apresentada por ele

\footnotetext{
${ }^{1}$ Usa-se a expressão ps para representar o termo posição, tendo em vista que em alguns e-book as páginas são tratadas como posição.
} 
como uma das fases de uma engenharia didática ${ }^{2}$, a que ele entende como orientação metodológica de pesquisa.

Há outros teóricos da área do ensino de Ciências e Matemática que apresentam proposições de SD baseadas nas concepções de ensino/aprendizagem de Ausubel, bem como de Freire, fundamentando, dessa forma, suas SDs a partir das definições das teorias elaboradas por eles.

Ausubel é o autor da teoria da aprendizagem significativa, a qual parte da ideia de que, no processo de ensino, deve-se pautar no conhecimento que o estudante já possui (subsunçor) para, com base nele, obter novos conhecimentos. Logo, para Ausubel, a nova informação se ancora em subsunçores da estrutura cognitiva de quem aprende. Para haver a assimilação, o processo de aquisição e organização do novo conhecimento pelo estudante, é necessário que o conteúdo a ser aprendido seja potencialmente significativo para o aprendiz e que este manifeste disposição de relacionar o novo material de maneira substantiva e não-arbitrária à sua estrutura cognitiva. Baseada em conhecimentos de caráter conceitual, essa abordagem depende muito mais das relações que esses conceitos estabelecem em si que do número de conceitos presentes. Ausubel evidencia a importância de planejar o conteúdo a ser ministrado buscando seguir quatro princípios norteadores: diferenciação progressiva; reconciliação integradora; organização sequencial; e consolidação (Moreira, 2007).

Freire é frequentemente lembrado pelos educadores e pesquisadores por ser o idealizador de uma proposta de ensino com base na concepção problematizadora da educação pela qual é possível estabelecer uma relação dialógica entre educador e educando. Logo, para ele, a dialogicidade é a essência da educação (Freire, 1987).

Não é intento neste estudo realizar um juízo de valor sobre a definição correta para uma SD. Pretende-se evidenciar diferentes conceitos de SD de modo a contribuir com a compreensão do objeto de estudo. Logo, cada conceito tem sua perspectiva e base teórica e epistemológica, sendo que se deve observar tais bases quando da análise de uma SD..

\section{Análise de trabalhos acadêmicos que apresentam como objeto de estudo uma proposta de Sequência Didática.}

Em setembro de 2000, foi criada, na Capes, a área 46, de Ensino de Ciências e Matemática. Embora tal criação tenha sido um fator de incentivo às pesquisas na área, entende-se que, antes desse período, pesquisadores de diversas áreas do conhecimento passaram a estudar sistematicamente o ensino e a aprendizagem das Ciências e Matemática. Essa ação se consolidou nas décadas de 80 a 90 com o surgimento de associações específicas de ensino como a SBEM (Sociedade Brasileira de Educação Matemática), a SBenBio (Sociedade Brasileira de Ensino de Biologia) e a Abrapec (Associação Brasileira de Pesquisa em Educação em Ciências) (Nardi, 2015).

Com o intento de analisar os trabalhos desenvolvidos na área de Ciências e Matemática, realizouse uma busca de dissertações e teses envolvendo uma proposta de Sequência Didática na Capes. Apareceram 3236 obras com referência ao termo na inclusão do descritor "sequência didática" (com aspas) junto à plataforma de dissertações e teses da agência. Com a aplicação dos filtros: ano (2015, 2016, 2017, 2018, 2019); área de conhecimento e área de concentração (Ensino de Ciências e Matemática), o quantitativo de trabalho foi para 220, sendo que 149 deles continham o trabalho em arquivo, enquanto somente 105 apresentaram uma Sequência Didática na estrutura do trabalho.

Observa-se que, dos 105 trabalhos analisados, 75 são da área de Ciências, enquanto 30 são da Matemática. Vê-se também que a maioria (101) é produto de atividades desenvolvidas em Programa de Mestrado Profissional, enquanto 04 são atividades desenvolvidas em programa de Doutorado.

\footnotetext{
${ }^{2}$ São estas as 4 fases da engenharia didática: "análises preliminares; concepção e análise a priori; aplicação de uma sequência didática e a análise a posteriori e a avaliação” (PAIS, 2015, ps. 1507).
} 
Escolheu-se apresentar a estrutura de sequência didática de 10 trabalhos, pois entende-se que eles representam as bases das SDs dos demais.

\subsection{Abordagens teóricas utilizadas pelos autores nos trabalhos acadêmicos com objeto de estudo uma Sequência Didática.}

A partir dos dados representados no gráfico a seguir, observa-se que as Sequências Didáticas tidas como objeto de estudo pelos autores dos trabalhos acadêmicos analisados foram pautadas nas abordagens teóricas das obras de: Freire, Delizoicov, Zabala, Guimarães e Giordan, Carvalho, Pais e Ausubel, entre outros.

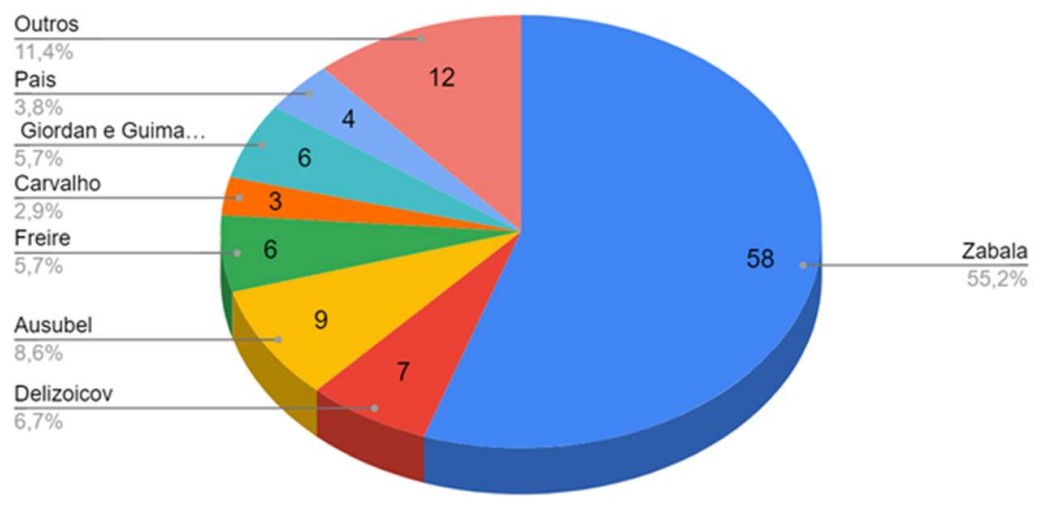

Gráfico 1: Aportes teóricos sobre as SDs utilizados nos trabalhos acadêmicos da área do ensino de Ciência e Matemática no Brasil, 2015-2020.

FONTE: Elaborado pelos autores, 2020.

Nos trabalhos que utilizaram Zabala como aporte teórico, a definição de sequência didática enfatiza a proposta pelo autor, que énsa a SD como "um conjunto de atividades ordenadas, estruturadas e articuladas para a realização de certos objetivos educacionais, que têm um princípio e um fim conhecidos tanto pelos professores como pelos alunos" (Zabala, 1998, p. 18). Ainda de acordo com o autor, a Sequência Didática deve ser entendida como um critério que permite identificações e caracterizações preliminares na forma de ensinar, não sendo apenas um tipo de tarefa.

Os 58 trabalhos que apresentam Zabala como aporte teórico estão distribuídos da seguinte forma: 29,3\% (17) trabalhos em 2015, 13,8\% (8) em 2016, 12,1\% (7) em 2017, 13,8\% (8) em 2018 e 31\% (18) trabalhos no ano de 2019. Desses, 02 autores, Fagundes (2015) e Lima (2019), utilizam Zabala em suas fundamentações teóricas, sendo que as estruturas de Sequência Didática são pautadas em outros autores. Lima (2019) utiliza os 3 Momentos Pedagógicos (3MP) desenvolvido por Delizoicov com base em Freire. $\mathrm{O}$ autor relata, juntamente com alunos da Educação de Jovens e Adultos de uma escola da cidade de Jataí-GO uma SD, que visa ensinar Física na EJA, o início a partir da sondagem dos conhecimentos prévios dos alunos. O produto educacional da atividade foi uma SD com título "Horário de Verão em Debate" (Lima, 2019, p.7).

Fagundes (2015), utiliza os pressupostos metodológicos e pedagógicos (diálogo e problematização) defendidos principalmente por Zabala, Berbel e Paulo Freire. Para a elaboração da 
sequência didática, a metodologia da problematização descrita por Berbel foi adotada, e seguiram as etapas do Arco de Maguerez ${ }^{3}$ : definição do problema/observação da realidade, pontos-chave, teorização, hipóteses de solução e aplicação da realidade (Fagundes, 2015).

Os autores Castro (2019) e Carvalho (2016) combinaram a teoria de Zabala (1998) com a metodologia de ensino SEIs (Sequências de Ensino Investigativo). As SEIs têm por filosofia uma proposta de ensino com base na investigação e são compostas pelas seguintes etapas: problematização; levantamento e testes de hipóteses; experimentação em grupo; registro escrito ou por desenho das ideias principais; pesquisa e socialização dos dados ${ }^{4}$.

Os demais 54 trabalhos seguiram as particularidades teóricas de Zabala (1998), no tocante à estrutura das sequências didáticas.

Dos 6 trabalhos que usaram Freire como aporte teórico, vê-se a inclusão do autor para fundamentar uma sequência didática como uma estratégia pedagógica problematizadora. Dois desses trabalhos - Moreira (2015) e Saugo (2016) - usaram ou mesclaram teorias de outros autores na construção das SDs apresentadas. Moreira (2015) apresentou uma Sequência Didática ancorada nas teorias e métodos de Zabala (1980) e de Paulo Freire (1996) e Ausubel (1996), com o tema: O Sol, a Terra e os Seres Vivos. (p.15). As atividades da SD foram planejadas para serem integradoras, e para tal o autor utilizou-se de diferentes estratégias, culminando na estrutura com as seguintes atividades: avaliação dos conhecimentos prévios dos alunos; introdução do tema; exploração; avaliação da aprendizagem e revisão da aprendizagem (Moreira, 2015).

Saugo (2016) utiliza uma sequência investigativa baseada em Ponte, Brocado e Oliveira (2009). Para os autores, investigar é buscar compreender o que ainda não se sabe. Na visão dos matemáticos, investigar é descobrir relações entre objetos matemáticos conhecidos ou desconhecidos, buscando identificar as respectivas propriedades. A investigação Matemática foi realizada a partir de quatro momentos: “[...] reconhecimento da situação, exploração preliminar e formulação de questões; [...] formulação de conjecturas (hipóteses); [...] realização de testes, execução e refinamento das conjecturas; [...] demonstração, argumentação do trabalho realizado" (Saugo, 2016, p. 21).

Observa-se nos 7 trabalhos que utilizaram Delizoicov como aporte teórico que há a menção do autor como seguidor da estratégia didática Freiriana, enfatizando a importância da problematização efetiva de temas a serem desenvolvidos em sala de aula, de modo que o tema envolva e instigue o aluno, para que ele se esforce na resolução do problema, potencializando o processo de ensino-aprendizagem. A estrutura de sequência didática seguida por Delizoicov é a estrutura metodológica dos três momentos pedagógicos: problematização inicial, organização do conhecimento e aplicação do conhecimento.

Araújo (2018), ancorada na pedagogia de Paulo Freire, elaborou, aplicou e analisou uma sequência didática estruturada na metodologia dos 3 MP de Delizoicov. A SD foi planejada e desenvolvida com o objetivo de discutir a sexualidade a partir das necessidades de saberes dos estudantes de uma turma do Ensino Médio de uma escola pública estadual capixaba, resultando em produto educacional por meio de atividades sistematizadas para o alcance dos objetivos planejados.

Ausubel foi usado em 9 trabalhos acadêmicos como suporte teórico inicial para a defesa da elaboração de uma sequência didática, como em Maciel (2015). Os autores que apresentaram Ausubel em suas fundamentações teóricas recordam à sua teoria em relação à ação didática sobre influência do fator estratégia de ensino-aprendizagem. Esses trabalhos estão divididos nas áreas de Química e Física, abordando temas como: física quântica, determinação da constante de planck, soluções químicas, termodinâmica, conservação da energia, eletromagnetismo, rotação, conteúdos polímeros e hidrodinâmica.

\footnotetext{
${ }^{3}$ O Método proposto por Charlez Maguerez, em 1966, e que ficou conhecido como "Arco de Maguerez propõe a observação de uma realidade/situação de vários ângulos, a qual possibilite que o estudante ou pesquisador verifiquem os problemas existentes". (Fagundes, 2015, p. 36).

${ }^{4}$ Essa metodologia é discutida no ensino de Ciências por Anna de Carvalho que também foi referenciada no trabalho.
} 
Foram encontrados 3 trabalhos que utilizaram Carvalho (1995 e outros) para fundamentar a atividade proposta. Dos autores que embasaram suas Sequências Didáticas na autora, há diferentes tipos de situações problematizadoras, questionadoras e de diálogo, envolvendo estratégias que buscam levar os estudantes a assimilar o conhecimento de forma autônoma.

Observou-se que Cruz (2016), mesmo tendo Carvalho como aporte teórico, apresenta sua Sequência Didática sobre o tema Fármacos Ansiolíticos com o intuito de investigar as potencialidades do ensino e aprendizagem baseados na resolução de problemas (EABRP). A abordagem utilizada para conteúdos de química orgânica no ensino médio foi avaliada com base na Teoria da Atividade de Leontiev, que utiliza as seguintes categorias: "objetivo, ações, sujeitos, sistema de operações e resultados" (Cruz, 2016, p. 19).

Guimarães e Giordan (2011 e outras) foram referenciados em 6 dos trabalhos analisados. Nesses, a estrutura proposta de sequência didática apresentada seguiu a defendida pelos autores, qual seja: "título, público-alvo, problematização, objetivos gerais, objetivos específicos, conteúdos, dinâmicas, avaliação, referências e bibliografia utilizada" (Guimarães e Giordan apud Souza e Sondermann, 2018, p.137). Nos trabalhos em que os autores foram referenciados, observou-se a predominância do ensino de Física com o apoio de recursos tecnológicos.

A exemplo dos trabalhos apresentados, tem-se a SD proposta por Santos (2017), que foi intitulada "Gincana da Física Térmica", apoiada no uso de passatempos on-line, com a utilização do software HP, sendo o passatempo do tipo JQuiz (jogo de perguntas e respostas). Todo o processo de elaboração, validação e aplicação da SD que utilizou o recurso dos passatempos on-line como aporte pedagógico ao ensino sobre o tema Física Térmica foi baseado na estrutura apresentada por Guimarães e Giordan (2011 e outras).

Pais (2015) foi referenciado em 4 trabalhos, todos eles voltados ao ensino de conteúdos matemáticos, como o de Germano (2016). Contudo, Germano (2011) propôs uma sequência didática tendo fundamentação na Teoria das Situações Didáticas (TSD) de Guy Brousseau (2008), a qual afirma que as situações didáticas devem se apresentar como um instrumento científico, integrando as contribuições de várias disciplinas para aperfeiçoar o ensino da matemática. O produto educacional do trabalho de Germano (2016) foi um caderno de atividades baseado em uma Sequência Didática (SD) sobre o ensino de números complexos apoiado no uso do GeoGebra para colaborar com os professores de Matemática. A SD apresentada pelo autor possuía 9 situações, sendo elas: A, B, C, D, E, F, G, H e I, todas elas divididas em: tema; conteúdo matemático; objetivo; estrutura: recursos materiais, conhecimentos prévios; situação de: proposta, formulação e de validação.

Da análise da abordagem teórica dos 93 trabalhos, conclui-se que 93,5\% (87), usaram o mesmo aporte para ambos os momentos, fundamentação teórica e estruturação da SD, e apenas 6,5\% (6), usaram ou mesclaram a estrutura das Sequências Didáticas com abordagens de teóricos diferentes dos empregados no referencial teórico.

Os 12 aportes teóricos mencionados no gráfico 1 como 'outros' tratam-se de Machado (2002), Villani e Nascimento (2003), Pietrocola (2006), Ferreira (2008), Santos (2009), Pinheiro, Abar e Sá (2012), Monteiro (2013), Vale e Barbosa (2015), Fazenda (1998), Vygotsky (1999), Burke (1969) e Binet (17861856).

\subsection{Estruturas das sequências didáticas expressas em trabalhos acadêmicos defendidos no Brasil na área de Ciências e Matemática.}


Visto que foram verificados trabalhos dos anos de 2015 a 2019, e dentre estes foram encontrados 105 que apresentaram Sequências Didáticas, categorizou-se as estruturas das SDs encontradas em duas. Logo, observou-se que essas duas estruturas representam a maioria das SDs analisadas na pesquisa. Destaca-se a seguir a primeira estrutura selecionada. Para exemplificá-la, buscou-se apresentar um(a) autor (a)/estrutura em cada ano.

\begin{tabular}{|c|c|c|c|c|}
\hline \multicolumn{5}{|c|}{ Estrutura 1 das Sequências Didáticas em: } \\
\hline Luz (2015) & Oliveira (2016) & Gehrke (2017) & Ribeiro (2018) & Castro (2019) \\
\hline $\begin{array}{l}\text { Questionário } \\
\text { Inicial; }\end{array}$ & $\begin{array}{l}\text { Apresentação do } \\
\text { Projeto de } \\
\text { Pesquisa e } \\
\text { Questionário } \\
\text { Inicial; }\end{array}$ & Teste diagnóstico; & Apresentação; & Questionário Inicial; \\
\hline Introdução; & $\begin{array}{l}\text { Problematização } \\
;\end{array}$ & $\begin{array}{l}\text { Questionário inicial } \\
\text { para análise do } \\
\text { conhecimento prévio; }\end{array}$ & Questionário inicial; & $\begin{array}{l}1^{\circ} \text { Momento: } \\
\text { Apresentação } \\
\text { Situação Problema } \\
\text { Formulação } \\
\text { Hipóteses; }\end{array}$ \\
\hline $\begin{array}{l}\text { Situação } \\
\text { problema; }\end{array}$ & Discussão; & $\begin{array}{l}\text { Registro das respostas } \\
\text { dos alunos às } \\
\text { atividades; }\end{array}$ & Aplicação do Jogo; & $\begin{array}{l}2^{\circ} \quad \text { Momento: } \\
\text { Orientação à pesquisa e } \\
\text { Teste das Hipóteses; }\end{array}$ \\
\hline $\begin{array}{l}\text { Resolução das } \\
\text { atividades; }\end{array}$ & $\begin{array}{l}\text { Atividades } \\
\text { Experimentais; }\end{array}$ & Atividade & Experimentação; & $\begin{array}{l}3^{\circ} \text { Momento: } \\
\text { Sistematização do } \\
\text { Conhecimento; }\end{array}$ \\
\hline \multirow[t]{2}{*}{$\begin{array}{l}\text { Questionário } \\
\text { Final. }\end{array}$} & \multirow[t]{2}{*}{$\begin{array}{l}\text { Questionário } \\
\text { Final. }\end{array}$} & \multirow[t]{2}{*}{ Questionário final. } & Aplicação do Jogo; & \multirow[t]{2}{*}{$\begin{array}{l}4^{\circ} \text { Momento: } \\
\text { Questionário Final da } \\
\text { Atividade de avaliação } \\
\text { (aplicação } \\
\text { conhecimento). }\end{array}$} \\
\hline & & & Questionário final. & \\
\hline
\end{tabular}

Quadro 1: Sequências Didáticas apresentadas em trabalhos acadêmicos defendidos entre 2015 a 2019: estrutura 1. FONTE: Elaborado pelos autores com base nas referências consultadas, 2020.

A partir das sequências apresentadas pelos autores Luz (2015), Oliveira (2016), Gehrke (2017), Ribeiro (2018), Castro (2019), que foram selecionadas a partir da similaridade e pontos - chaves, constatase que esta está dividida em 5 momentos, sendo eles: apresentação e questionário inicial; introdução; problematização; discussão e resolução das atividades; e, questionário final.

A seguir, estão elencadas mais 5 Sequências Didáticas que apresentam a mesma estrutura. Essas são precedidas pelos seus autores, sendo uma de cada ano.de SD no ensino de Ciências e Matemática 
pelo Brasil. Observou-se também que autores mesclaram aportes teóricos para fundamentar tanto o referencial como a estrutura das SDs apresentadas em seus trabalhos.

\begin{tabular}{|c|c|c|c|c|}
\hline \multicolumn{5}{|c|}{ Estrutura 2 das Sequências Didáticas em: } \\
\hline Abreu (2015) & Celante (2016) & Santos (2017) & Areias (2018) & Cora (2019) \\
\hline Tema; & Título; & Público Alvo: & Público alvo; & Título; \\
\hline Público Alvo; & Público Alvo; & Problematização: & Objetivo geral; & Público Alvo; \\
\hline Problematização; & Problematização; & Objetivo Geral: & Problematização; & $\begin{array}{l}\text { Problematizaç } \\
\text { ão }\end{array}$ \\
\hline Objetivos Gerais; & Objetivo Geral; & Conteúdo e Métodos; & $\begin{array}{l}\text { Organização do } \\
\text { conhecimento; }\end{array}$ & $\begin{array}{l}\text { Objetivo } \\
\text { Geral }\end{array}$ \\
\hline $\begin{array}{l}\text { Objetivos } \\
\text { Específicos; }\end{array}$ & $\begin{array}{l}\text { Conteúdos } \\
\text { Métodos; }\end{array}$ & \multirow{3}{*}{$\begin{array}{ll}\text { Avaliação } & \text { da } \\
\text { aprendizagem. } & \end{array}$} & $\begin{array}{l}\text { Aplicação do } \\
\text { conhecimento; }\end{array}$ & $\begin{array}{l}\text { Conteúdos e } \\
\text { Métodos: } \\
\text { - Aula } \\
\text {-Objetivos } \\
\text { Específicos } \\
\text { - Conteúdos }\end{array}$ \\
\hline Conteúdo; & $\begin{array}{l}\text { Objetivos } \\
\text { Específicos; }\end{array}$ & & \multirow[t]{2}{*}{ Avaliação. } & Avaliação; \\
\hline Avaliação. & Avaliação. & & & $\begin{array}{l}\text { Referencial } \\
\text { Bibliográfico; } \\
\text { Bibliografia } \\
\text { consultada. }\end{array}$ \\
\hline
\end{tabular}

Quadro 2: Sequências Didáticas apresentadas em trabalhos acadêmicos defendidos entre 2015 a 2019: estrutura 2. FONTE: Elaborado pelos autores com base nas referências consultadas, 2020.

Os autores relacionados no quadro supracitado - Abreu (2015), Celante (2016), Santos (2017), Areias (2018) e Cora (2019) - apresentam uma estrutura de Sequência Didática proposta por Giordan e Guimarães (2011), Zabala (1998), que constitui-se de: título, público alvo, problematização, objetivos gerais, objetivos específicos, conteúdos, dinâmicas, avaliação, referências bibliográficas e bibliografia empregada. Esta também contempla os três momentos pedagógicos cunhados por Delizoicov: problematização inicial; organização do conhecimento e aplicação do conhecimento.

Ao analisar as duas estruturas de SD apresentadas nos quadros I e II deste artigo, observa-se que a problematização é o seu ponto-chave e o que diferencia algumas delas é a proposição das situações problemas como etapa inicial, ou não, da base da SD. 


\section{Considerações finais}

A base referencial das Sequências Didáticas defendidas nos trabalhos acadêmicos analisados, em sua maioria, parte de Zabala (1998), mesmo que se tenha observado o surgimento de novas propostas de conceito e de prática de SD no ensino de Ciências e Matemática pelo Brasil. Observou-se também que autores mesclaram aportes teóricos para fundamentar tanto o referencial como a estrutura das SDs apresentadas em seus trabalhos.

Destaca-se que a estrutura da SD, pautada na proposição dos 3 Momentos Pedagógicos (3MP), desenvolvida por Delizoicov com base em Freire, tem sido progressivamente utilizada pelos pesquisadores no Brasil e que há continuação do uso da problematização e situações-problemas, respectivamente, como base para o processo de ensino e como avaliação do conhecimento assimilado pelos estudantes.

As proposições de diferentes atividades problematizadoras, questionadoras e de diálogo são os pontos comuns nas diferentes SDs analisadas nesse trabalho. As SDs se distinguem devido às suas particularidades, sendo que o objetivo do seu uso converge para o de promover a aprendizagem.

A tentativa de apreender as estruturas das SD em estudo somente fará sentido na medida em que se verificar as SD sendo desenvolvidas. Uma mesma estrutura de SD pode assumir características diferenciadas a depender do professor, do estudante, do tempo e do espaço em que será utilizada. Mesmo havendo produtos educativos disponíveis aos educadores sobre determinados conteúdos, as estratégias metodológicas utilizadas podem e devem variar de acordo com os interesses e realidades dos estudantes e professores, de forma que haja, como defendeu Ausubel, uma aprendizagem significativa dos conteúdos ministrados por parte dos estudantes.

Visualizar a SD como uma atividade que requer a participação ativa tanto dos estudantes quanto professores se faz necessário. Por meio dela, o professor pode melhorar sua atuação em sala, os estudantes podem aprender de modo significativo, atingindo assim os objetivos educacionais.

\section{Agradecimentos}

Aos professores do Programa de Pós-Graduação em Educação em Ciências e Matemática da Rede Amazônica de Educação em Ciências e Matemática -PPGECEM/REAMEC- pela disposição em colaborar com a formação de professores doutores na e para a Região Amazônica, Brasil. 


\section{Referências}

Abreu, R. O. (2015). A realidade aumentada como recurso didático alternativo para o ensino de astronomia: uma sequência didática para o estudo do sistema solar. 129f. 2015 (Mestrado em Educação para Ciências e Matemática), Instituto Federal de Educação, Ciência e Tecnologia de Goiás, Jataí.

Araújo, B. O. P. de. (2018). Proposta pedagógica e considerações sobre uma educação sexual mais humana e emancipatória. 2018. 185f. (Mestrado Profissional em Educação em Ciências e Matemática) Instituição de Ensino: Instituto Federal de Educação, Ciência e Tecnologia do Espírito Santo, Vila Velha Biblioteca Depositária: Biblioteca Nilo Peçanha do IFES.

Areias, G. B. (2018). Aprendizagem móvel em espaços educativos: uso do celular no contexto do ensino fundamental. 2018. 105f. (Mestrado Profissional em Educação em Ciências e Matemática) Instituto Federal de Educação, Ciência e Tecnologia do Espírito Santo, Vila Velha biblioteca depositária: biblioteca do centro de referência em formação e em educação a distância (CEFOR/IFES).

Brasil, 2020. Catálogo de Teses e Dissertações. Disponível em: https://catalogodeteses.capes.gov.br/catalogoteses/\#!/. Acesso em: 17 fev. 2020.

Carvalho, A. M. P. de., \& GARRIDO, E., \& CASTRO, R. S. de. (1995). El papel de las actividades em la construcción del conocimiento em classe. Investigación em la Escuela, (25), p. 60-70, 1995. Disponível em: https://idus.us.es/handle/11441/59632. Acesso em: 12 jul. 2020.

Carvalho, N. P. A. (2016). Horta escolar: contribuições da interdisciplinaridade e de atividades investigativas para a alfabetização científica. 2016 164f. (Mestrado Profissional Em Educação para Ciências e Matemática Instituição de Ensino), Instituto Federal de Educação, Ciência e Tecnologia de Goiás, Jataí Biblioteca Depositária: Biblioteca do Instituto Federal de Goiás - Campus Jataí.

Castro, M. do C. de. (2019). Análise de uma sequência didática com enfoque CTS e ensino por investigação a partir da temática "água potável". 2019 171f. (Mestrado Profissional em Ensino de Ciências e Matemática) Instituição de Ensino: Instituto Federal de Educação, Ciência e Tecn. de São Paulo, São Paulo, Biblioteca Depositária: Biblioteca Francisco Montojos - IFSP/SPO.

Celante, G. X. M. (2016). Momentos pedagógicos sobre a destilação da cachaça: da Contextualização Histórica ao Contexto Social. IFES, 2016. 101f. Dissertação (Mestrado em Educação em Ciência e Matemática) Instituto Federal do Espírito Santo, Programa de Pós-graduação em Educação em Ciências e Matemática. Vitória, ES.

Cora, R. A. (2019). Uma viagem às origens: o ensino de evolução bumana a partir de uma sequência didática na perspectiva da alfabetização cientifica. 2019. 119f. Dissertação (Mestrado Profissional em Educação em Ciências e Matemática) - Programa de Pós-Graduação em Ensino de Ciências e Matemática - Instituto Federal do Espírito Santo, Vitória, ES.

Cruz, M. (2016). Sequência Didática sobre fármacos ansiolíticos baseada na abordagem de resolução de problemas: análise a partir de aspectos da teoria da atividade de Leontiev, 2016. 164 f. (Mestrado em Ensino das Ciências). Universidade Federal Rural de Pernambuco, Recife, PE.

Delizoicov, D.; (2008). La Educación en Ciencias y la Perspectiva de Paulo Freire. Alexandria: Revista de Educação em Ciência e Tecnologia, v.1, n.2, p.37-62, julho, 2008. Disponível em: 
https://www.researchgate.net/publication/242167234_La_Educacion_en_Ciencias_y_la_Perspectiva_ de_Paulo_Freire. Acesso em: 12 jul. 2020.

Delors, J. (Coord.). (2003). Educação: um tesouro a descobrir. 2ed. São Paulo: Cortez, Brasília, DF: MEC/UNESCO.

Fagundes, D. S. (2015). Criação, aplicação e avaliação de uma sequência didática para o curso de cuidadores de idosos apoiada na metodologia da problematização. 2015. 136f. (Mestrado Profissional em Ensino Instituição de Ensino) Pontifícia Universidade Católica de Minas Gerais, Belo Horizonte.

Freire, P. (1987). Pedagogia do oprimido. Rio de Janeiro, RJ: Paz e Terra.

Gehrke, T. T. (2017). Trilhos matemáticos como contexto para o ensino e a aprendizagem de geometria espacial com estudantes do terceiro ano do Ensino Médio. 2017. 117f. (Mestrado Em Ensino de Ciências e Matemática). Universidade Franciscana, Santa Maria Biblioteca Depositária: Centro Universitário Franciscano.

Germano, J. G. da C. (2016). Uma proposta de abordagem dos números complexos com o uso do Geogebra, 2016131 f. (Mestrado Profissional em Ensino de Ciências e Matemática). Universidade Federal do Ceará, Fortaleza Biblioteca Depositária: Biblioteca do Curso de Matemática (bcm) Ufc.

Gil, A. C. (2010). Como elaborar Projetos de Pesquisa. São Paulo, SP: Atlas.

Guimarães, Y. A. F.; \& GIORDAN, M. (2011). Instrumento para construção e validação de sequências didáticas em um curso a distância de formação continuada de professores. In: VIIII Encontro Nacional de Pesquisa em Educação em Ciências, 2011, Anais... Campinas. Educação em Ciências. Campinas: USP, 2011. Disponível em: http://abrapecnet.org.br/atas_enpec/viiienpec/resumos/R0875-2.pdf. Acesso em: 13 jul. 2020 .

Lima, F. S. R. (2019). O horário de verão em debate: uma proposta para o ensino de Física na EJA baseada nos três momentos pedagógicos. 2019. 130f. Dissertação (Mestrado Profissional em Educação para Ciências e Matemática) - Programa de Pós-Graduação em Educação para Ciências e Matemática - Instituto Federal de Goiás, Jataí, 2019.

Luz, L. H (2015). Matemática Financeira no Ensino Fundamental: uma questão para o $7^{\circ}$ Ano, 2015, $115 f$. (Mestrado em Ensino de Ciências e Matemática). Universidade Luterana do Brasil, Canoas Biblioteca Depositária: Martin Lutero.

Maciel, G. S. (2015). Proposta de uma Sequência Didática sobre tópicos de Física Quântica através do uso de simulações Computacionais e da Determinação da Constante de Planck com Leds Aplicado ao Ensino Médio, 2015, 92f. (Mestrado Profissional em Ensino de Física). Universidade Federal do Espírito Santo, São Paulo, SP.

Moreira, A. E. R. (2015). O sol, a Terra e os Seres Vivos: uma proposta de sequência didática para o ensino de Ciências na Educação de Jovens e Adultos. 2015. 97f. Dissertação (Mestrado profissional em Ensino de Ciências e Matemática) - Programa de Pós- Graduação em Ensino de Ciências e Matemática da Pontifícia Universidade Católica de Minas Gerais, Belo Horizonte, MG.

Moreira, M. A. (2007). Aprendizagem Significativa: da visão clássica à visão crítica. In: I Encuentro Nacional sobre Enseñanza de la Matemática, Anais... Tandil, Argentina. Disponível em: http://moreira.if.ufrgs.br/visaoclasicavisaocritica.pdf. Acesso em: 13 jul. 2020. 
Nardi, R. (2015). A pesquisa em ensino de Ciências e Matemática no Brasil. Editorial. Ciência \&̋ Educação. Bauru, vol.21, $\quad \mathrm{n}^{\circ} .2, \quad$ Apr./June, $2015 . \quad$ Disponível em: http://www.scielo.br/scielo.php?script=sci_arttext\&pid=S1516-73132015000200001. Acesso em: 17 fev. 2020.

Oliveira, M. M. de. (2013). Sequência didática formativa no processo de formação de professores. Petrópolis, RJ: Vozes.

Oliveira, T. de C. (2016). Educação CTS: uma experiência didática com o tema substâncias psicoativas, $217 \mathrm{f}$. (Mestrado Profissional em Ensino de Ciências e Matemática) Instituto Federal de Educação, Ciência e Tecnologia de São Paulo, São Paulo Biblioteca Depositária: IFSP.

Pais, L. C. (2015). Didática da Matemática: uma análise da influência francesa. Edição Kindle. Belo Horizonte: Autêntica Editora.

Ribeiro, R. K. P. (2016). Produção de significados utilizando o jogo planeta química com base na teoria da ação mediada. 138 f. (Mestrado em Ensino de Ciências e Matemática). Universidade Federal do Maranhão, São Luís, MA.

Sampaio, R.F., \& Mancini, M.C. (2007). Systematic review studies: a guide for careful synthesis of the scientific evidence. Rev. bras. fisioter. [online]. 2007, vol.11, n.1, pp.83-89. ISSN 1413-3555. http://dx.doi.org/10.1590/S1413-35552007000100013. Disponível em: http://www.scielo.br/pdf/rb.fis/v11n1/12.pdf. Acesso em: 22 set. 2019.

Santos, K. de F. dos (2017). O Ensino do conteúdo de soluções químicas sob a perspectiva da educação no campo com enfoque agroecológico. 2017. 91f. (Mestrado Profissional em Ensino de Ciências e Matemática) Fundação Universidade de Passo Fundo, Passo Fundo.

Saugo, C. (2016). Explorando a informática educativa como alternativa de ensino da geometria plana na educação básica. 2016. 94f. Dissertação (Mestrado em Ensino de Ciências e Matemática). Universidade de Passo Fundo, Passo Fundo, RS.

Silva, C. da C. e. (2019). Eletricidade no cotidiano para a EJA a partir dos três momentos pedagógicos. 2019. $70 \mathrm{f}$. Dissertação (Mestrado em Ensino de Ciências e Matemática). Instituto de Ciências Exatas e Geociências. Universidade de Passo Fundo, Passo Fundo.

Sousa, M. M. de. (2015). Dialogicidade, experimentação e aprendizagem cooperativa aplicadas ao ensino de ligações químicas e interações intermoleculares. 2015. 97f. (Mestrado Profissional em Ensino de Ciências e Matemática). Universidade Federal do Ceará, Fortaleza Biblioteca Depositária: Biblioteca Central da UFC.

Souza, M.A V. F. \& Sondermann, D. V. C. (2018). Ensinar e Aprender: caminhos e reflexões. Disponível em: https://educimat.ifes.edu.br/images/stories/ebook_Ensinar-e-Aprender.pdf. Acesso em: 29 ago. 2020.

Zabala, Antoni. (1998). A prática educativa: como ensinar. Porto Alegre, RS: Artmed. 


\section{Sobre os Autores}

\section{KÊNYA MARIA VIEIRA LOPES}

(D) ORCID: https://orcid.org/0000-0001-5930-5464

Mestra em Educação Agrícola pela Universidade Federal Rural do Rio de Janeiro, UFRRJ, Brasil.

Doutoranda do Programa de Pós-Graduação em Educação, em Ciências e Matemática da Rede Amazônica de Educação, Ciências e Matemática (PPGECEM/REAMEC) da Universidade Federal de Mato Grosso, UFMT, Brasil.

Professora no Instituto Federal de Educação, Ciência e Tecnologia do Tocantins, IFTO, Brasil.

E-mail:kenya@ifto.edu.br

\section{RITIANNE DE FÁTIMA SILVA DE OLIVEIRA}

(D) ORCID: https://orcid.org/0000-0002-6928-6348

Mestranda em Educação pela Universidade Federal do Tocantins, UFT, Brasil.

Professora da Educação Básica na Rede Municipal de Educação de Canaã dos Carajás, Brasil.

E-mail: ritianne19@hotmail.com

\section{IDEMAR VIZOLLI}

(D) ORCID: https://orcid.org/0000-0002-7341-7099

Doutor em Educação Matemática pela Universidade Federal do Paraná, UFPR, Brasil.

Professor no PPGECEM/REAMEC da Universidade Federal de Mato Grosso, e nos Programas de Graduação e Pós-Graduação da Universidade Federal do Tocantins, Brasil.

E-mail: idemar@uft.edu.br

\section{MARTA MARIA PONTIN DARSIE}

(D) ORCID: https://orcid.org/0000-0002-1255-6546

Doutora em Educação pela Universidade de São Paulo, Brasil.

Professora e Coordenadora Geral do PPGECEM/REAMEC da Universidade Federal de Mato Grosso, UFMT, Brasil.

E-mail:marponda@uol.com.br

Enviado em: 12 ago. 2020

Aprovado em: 21 set. 2020 